they are sick or wounded they will receive as good care, as high a class of medical and surgical service, as could possibly be obtained' in civil life. This is true because our best men have gone into the medical service, and the government is providing the medical departments with every facility necessary to give our soldiers the best medical care.

\section{THE LABELLING OF FAIR EXHIBITS AS AN AID TO AGRICULTURAL PRODUCTION}

IN past years and even at this time, when increased conservation and production of food is so desirable, the people of North America invest a tremendous sum in over 2,000 county fairs and similar agricultural exhibitions. This investment loses much of its effectiveness-perhaps more than half-because of lack of labels, scarcity of labels or imperfect labels.

By labels is not meant such labels as are used in the great museums where too much attention is given to the specimen and too little to the desirable effect of the exhibit or the effect of the label, if it be present at all. Over sixteen years' experience in the American Museum of Natural History, perhaps the largest museum on the continent, convinced me that useful labels are more rare and more valuable than the exhibits.

At the Central Canada Exhibition in Ottawa was once exhibited a very interesting hand-woven fabric apparently of farmer handiwork, but close examination of the exhibit failed to reveal where it was made, by what class of people, its value, or where such fabrics could be obtained. Otherwise intelligent people have been known to lay in a stock of fall fruit, part of which spoiled before the winter was over. A label at the fair on fruit preservation would have saved this loss. When one views the machinery at a fair he is often at a loss to know for what it may be used. Many similar examples could be given. Probably more than half the people who visit a fair grope their way through without understand- ing many of the exhibits. They go as a lark, but could learn at the same time things that would make them more useful to the whole country. An additional investment, small in proportion to the present whole cost of fairs, would change them from amusements or casual advertisements to educational institutions resulting in diffusing the best agricultural knowledge discovered by the government experts.

An additional investment of less than one cent per exhibit would provide suitable educational labels and probably double, if not multiply the productive national value of the fairs many fold. It is not proposed that each fair should write and print its own labels. This would mean that the ignorant or least skilled would write the labels, whereas we have intelligent and skilled specialists in provincial or national agricultural departments, as well as in agricultural colleges and experiment stations. It would also mean that there would be as many labels written as there are fairs, a tremendous overlapping of effort and expense, while one writing would do for all.

It is not advocated to label each exhibit, for instance each cow, but to label each breed. In the case of large exhibits with many individuals, as of Clydesdale horses, one label would be put at each end of each row of stalls and perhaps in one or more places between.

Perhaps labels should not be made in this particular way for everything in every fair, but for those things that are common to most of the fairs. One could take the list of exhibits at a typical fair and make a label for each class of exhibits, such as Holstein cows, Plymouth Rock chickens, northern spy apples, Hubbard squash and windmills. They would not be advertisements for any firm.

Each label should be written by the leading expert in that particular sort of exhibitbreed of cattle, swine, bee, wheat, potato, apple, gang plow, threshing machine, windmill, motor, or what not. This label should be criticised by many other experts and then rewritten by a man who is an expert in interpreting facts to the people-to farmers and 
others who are not scientists. Many an agricultural bulletin is not read or is thrown away by farmers because it is too technical or because what they wish to know is buried in hundreds of pages of detail too technical for their understanding. Possibly an expert advertising writer could condense the labels written by experts down to essentials and rewrite them in language understood by the average farmer. Such labels consequently could not give the name and address of the owner, price, or other local details, but each label should be an adequate article on the subject, including references to both the best literature and to that which is most available, such as experiment station reports. It should contain nothing that could be replaced by a more important statement. Possibly the labels would cover an $8 \times 12$ inch card. They would tell, for instance, which breed of cow was good for milk, which for beef, what to feed, when to water, the general values and all such useful information. They would help the city dweller to cooperate with the farmer, and also in connection with buying, storing, drying, or otherwise preserving food. They might assist mechanics to know better how to invent and to make farm machinery.

These labels could be printed by national or provincial governments and distributed to each fair management so that each exhibit might teach to the farmers and other citizens who need the knowledge the essentials of increasing and improving the country's food supply.

The labels may be bound into a book, or rather the same type may be used to print off a guide-book or elementary agricultural encyclopedia, thus killing two birds with one stone, as has been done in the case of the imperfect and incomplete preliminary edition of the Handbook of the Rocky Mountains Park Museum, where one type setting supplied a handbook and labels for 18 museums, a zoo, a paddock and other uses. The same labels may also be illustrated with lantern slides or moving pictures and thus serve as lecture notes which may be arranged in any desired order. If a local fair wishes to add advertise- ments or labels of unusual local products not common to all fairs, such as peanuts or sweet potatoes, these labels may be prepared and printed locally for binding in at the back. In case the local authorities wish such advertisements or labels to local products added in the body of the book, then the originating or central office may supply electros or matrix of the standard label matter.

This plan would give far more accurate labels and handbooks than if each fair had its relatively unexpert men compose the matter. It would also save the useless expense of each fair composing its own labels and setting its own type.

\section{Geological Survet,} Ottama, Canada

\section{HarLaN I. SMith}

\section{SCIENTIFIC EVENTS}

THE COORDINATION OF SCIENTIFIC PUBLICATION 1

THE coordination of scientific publication formed the subject of a recent conference arranged by the Faraday Society under the chairmanship of Sir Robert Hadfield, when a number of interesting problems bearing on the desirability of a fuller cooperation amongst our scientific and technical societies were discussed. Both in the reading and publication of papers there is, at present, a considerable amount of overlapping and lack of coordination, with the result that much valuable work is either lost or overlooked owing to communications being made to societies which are not especially associated with the subject-matter of the investigations concerned, and much benefit would undoubtedly result from a federation of interests in this respect. Whilst there is a general consensus of opinion that it is essential to maintain the individuality of each society in regard to the reading and publication of papers, and that any attempt to pool communications for later distribution by a central organization is undesirable, much effective cooperation could be secured between kindred societies by the arrangement of joint meetings and conferences with the object of

\footnotetext{
1 From Nature.
} 